0

doi:10.5004/dwt.2017.20369

\title{
Coating of reverse osmosis membranes with amphiphilic copolymers for biofouling control
}

\author{
Szilárd S. Bucs ${ }^{\text {a,* }}$, Rodrigo Valladares Linares ${ }^{\mathrm{a}}$, Nadia Farhat ${ }^{\mathrm{a}}$, Asif Matin ${ }^{\mathrm{b}}$, \\ Zafarullah Khanc, Mark C.M. van Loosdrecht ${ }^{\mathrm{d}}$, Rong Yange, Minghui Wangf, \\ Karen K. Gleason' ${ }^{\mathrm{f}}$ Joop C. Kruithofg, Johannes S. Vrouwenvelder ${ }^{\mathrm{a}, \mathrm{d}, \mathrm{g}}$
}

${ }^{a}$ King Abdullah University of Science and Technology (KAUST), Water Desalination and Reuse Center (WDRC), Division of Biological and Environmental Science and Engineering (BESE), Thuwal 23955-6900, Saudi Arabia, email:bucsszilard@kaust.edu.sa (S.S.Bucs),rodrigo.valladares@kaust.edu.sa (R.V.Linares),nadia.farhat@kaust.edu.sa (N. Farhat), johannes.vrouwenvelder@kaust.edu.sa (J.S.Vrouwenvelder)

${ }^{b}$ Center of Excellence for Scientific Research Collaboration with MIT, King Fahd University of Petroleum E Minerals, Dhahran 31261, Saudi Arabia, email: amatin@kfupm.edu.sa

${ }^{c}$ Mechanical Engineering, King Fahd University of Petroleum \& Minerals, Dhahran 31261, Saudi Arabia, email: zukhan@kfupm.edu.sa ${ }^{d}$ Department for Biotechnology, Faculty of Applied Sciences, Delft University of Technology, Van der Maasweg 9, 2629 HZ Delft, The Netherlands, email: M.C.M.vanLoosdrecht@tudelft.nl (M.C.M. Van Loosdrecht), j.s.vrouwenvelder@tudelft.nl (J.S.Vrouwenvelder) ${ }^{e}$ Harvard Medical School, Boston Children's Hospital, Boston, MA 02114, USA, email: rongyang@mit.edu(R. Yang)

${ }^{f}$ Chemical Engineering, Massachusetts Institute of Technology, Cambridge 02139, USA, email: kkgleasn@mit.edu (K.K. Gleason) ${ }^{8}$ Wetsus, European Centre of Excellence for Sustainable Water Technology, Oostergoweg 9, 8911 MA Leeuwarden, The Netherlands, email: joop.kruithof@wetsus.nl (J.C. Kruithof), hans.vrouwenvelder@wetsus.nl (J.S.Vrouwenvelder)

Received 19 September 2016; Accepted 8 November 2016

\section{A B S T R ACT}

Surface coating of membranes may be a promising option to control biofilm development and biofouling impact on membrane performance of spiral-wound reverse osmosis $(\mathrm{RO})$ systems. The objective of this study was to investigate the impact of an amphiphilic copolymer coating on biofilm formation and biofouling control. The coating was composed of both hydrophilic and hydrophobic monomers hydroxyethyl methacrylate (HEMA) and perfluorodecyl acrylate (PFA), respectively. Commercial RO membranes were coated with HEMA-PFA copolymer film. Long and short term biofouling studies with coated and uncoated membranes and feed spacer were performed using membrane fouling simulators (MFSs) operated in parallel, fed with water containing nutrients. For the long-term studies pressure drop development in time was monitored and after eight days the MFSs were opened and the accumulated biofilm on the membrane and spacer sheets was quantified and characterized. The presence of the membrane coating was determined using X-ray photoelectron spectroscopy (XPS) and Fourier transform infrared spectroscopy (FTIR). Results showed that the amphiphilic coating (i) delayed biofouling (a lower pressure drop increase by a factor of 3 and a lower accumulated active biomass amount by a factor of 6), (ii) influenced the biofilm composition (23\% lower polysaccharides and $132 \%$ higher protein content) and (iii) was still completely present on the membrane at the end of the biofouling study, showing that the coating was strongly attached to the membrane surface. Using coated membranes and feed spacers in combination with advanced cleaning strategies may be a suitable way to control biofouling.

Keywords: Biofouling control; Membrane surface modification; Membrane coating; Biofilm morphology; Amphiphilic copolymer

${ }^{*}$ Corresponding author. 


\section{Introduction}

The use of membrane filtration processes like nanofiltration (NF) or reverse osmosis (RO) for water desalination and reuse has a great potential to meet the growing demand for fresh water. One of the major drawbacks of membrane filtration is fouling, accumulation of unwanted material (particles, inorganics, organics and biomass) on the membrane surface. Membrane fouling causes reduction of the product water quantity and quality while increasing the operational costs. The most predominant fouling type is biofouling, excessive deposition and growth of biomass on the membrane surface causing an unacceptable performance decline [1-5].

Many research efforts have been carried out to reduce biofouling in membrane systems with focus on improvement of (i) pre-treatment, (ii) membrane module design and (iii) membrane surface modification. It was shown that the physicochemical properties (surface charge, roughness, hydrophilicity) of the membrane surface have an impact on membrane fouling [6]. It is generally accepted that hydrophilic membranes are more resistant to fouling [7]. Surface charge and membrane roughness are important factors influencing membrane fouling. Deposition of foulants is less likely on neutral or close to neutrally charged membrane surfaces $[7,8]$. Surface morphology has a significant role on membrane fouling, because foulants are more likely to be entrained by rougher topologies than by smoother membrane surfaces $[6,9]$.

Membrane coating is frequently proposed for surface modification of conventional $\mathrm{RO}$ membranes to avoid or reduce membrane fouling. Many studies showed that compared to uncoated membranes, less fouling was observed when membranes surfaces had a hydrophilic coating [10-15].

Amphiphilic copolymer coatings, containing both hydrophilic and hydrophobic groups have been used to reduce protein and bacterial adhesion to the membrane surface. Asatekin et al. [16] developed nanofiltration membranes with a selective, comb-like amphiphilic copolymer layer. The developed membranes showed a high resistance against biofouling with bovine serum albumin (BSA) during dead-end filtration experiments [16]. Bacterial adhesion to membranes coated with amphiphilic copolymers and the reversibility of the adhesion were tested using atomic force microscopy (AFM). Furthermore, the fouling resistance of the coated membrane and feed spacer was tested in short-term static bacterial adhesion tests as well as in long-term cross-flow filtration cells studies. Results showed no bacterial adhesion to the coated membrane during the static test, but adhesion was observed during the cross-flow filtration studies [17]. Baxamusa and Gleason [17] used amphiphilic copolymers to reduce protein adsorption to membrane surfaces. Static protein adsorption experiments showed that less proteins adsorbed to the membranes coated with copolymers than for the membrane coated with either of the two homopolymers [17], suggesting that membrane coatings with amphiphilic copolymers could significantly reduce biofouling of membrane filtration systems.

The impact of amphiphilic coating on water permeation for different $\mathrm{RO}$ membranes was evaluated by Matin et al. [18]. In their study uncoated and coated membranes from
SWC1 (Hydranautics), TF-RO-SG (GE Osmonics, Inc.), and TFC-HR (Koch Membrane Systems, Inc.) were evaluated. All coated membranes contained a copolymer film of identical thickness $(20 \mathrm{~nm})$ and $\sim 40 \%$ PFA content. Since the HEMA-PFA copolymer is less permeable to water molecules as the polyamide top layer of the $\mathrm{RO}$ membrane, a decrease in water permeability was observed. The highest flux decline was $38 \%$ for the SWC1 membrane and the lowest $13 \%$ for the TFC-HR membranes. The impact of the applied coating on water permeation was showed by Matin et al. [18] and was not the objective of this study.

In membrane systems, biofilm growth is defined as biofouling when it causes a performance decline exceeding a certain threshold. In practice, this threshold is defined as $15 \%$ increase in feed channel pressure drop or $15 \%$ reduction in permeate flux to maintain the necessary permeate quantity [19]. In systems suffering from biofouling cleaning cycles are governed by the pressure drop over the feed channel. Therefore, in both spiral wound NF and RO systems biofouling is predominantly a feed channel pressure drop problem $[20,21]$.

The objective of this study was to investigate the impact of a surface coating by amphiphilic copolymers on biofilm formation and biofouling control in membrane systems. The coating was composed of hydrophilic hydroxyethyl methacrylate (HEMA) and hydrophobic perfluorodecyl acrylate (PFA). The membranes were characterized, and the presence of the amphiphilic coating was inspected before and after the biofouling studies by X-ray photoelectron spectroscopy (XPS) and Fourier transform infrared spectroscopy (FTIR) [22,23]. To evaluate the potential of the amphiphilic coating on biofilm formation and biofilm control (i) static, short-term bacterial adhesion and (ii) longterm biofouling studies were performed using membrane fouling simulators (MFSs).

\section{Material and methods}

\subsection{Amphiphilic membrane coating procedure}

The two monomers, PFA and HEMA were heated in separate crucibles to $80^{\circ} \mathrm{C}$ and $70^{\circ} \mathrm{C}$ respectively while the initiator, tert-butyl peroxide was kept at room temperature. The relative flow rates of the monomer gases and the initiator were adjusted to obtain a content of $40 \%$ PFA in the copolymer. The commercial RO membrane (Koch Membrane Systems, Inc., USA) samples were stored at $30^{\circ} \mathrm{C}$.

The copolymerization took place directly on to the active layer of the membrane and resulted in the formation of the copolymer film with a target thickness of around $20 \mathrm{~nm}$. Membrane film growth was monitored in situ by laser interferometry with the laser focused on a single point on a silicon wafer placed adjacent to the membrane sample. The film deposition was terminated once the laser interferometry indicated attainment of the desired thickness on the silicon wafer [24].

\subsection{Membrane characterization}

The coated and uncoated membranes were characterized before and after the long-term biofouling studies to confirm the presence/absence of the coating. 
The zeta potential was determined by a SurPASS Complete surface analyzer (Anton Paar Inc, USA) at a pH range from 3 to 10 at $0.1 \mathrm{mM}$ ionic strength. Atomic force microscopy (AFM) was used to quantify membrane roughness (Atomic Force Microscope, Keysight Technologies, Inc., CA, USA).

X-ray photoelectron spectroscopy (XPS) was used to confirm the presence of the copolymer film on the modified membranes. The analyses were conducted on an Axis Ultra DLD system under ultra-high vacuum conditions $\left(1.6 \times 10^{-12}\right.$ bar). The surface scan was performed in the binding energy range $0-1000 \mathrm{eV}$ with a resolution of $1 \mathrm{eV}$. High-resolution scans of $\mathrm{C} 1 \mathrm{~s}, \mathrm{~F} 1 \mathrm{~s}$ and $\mathrm{O} 1 \mathrm{~s}$ were conducted under similar conditions with $0.05 \mathrm{eV}$ steps, pass energy $20 \mathrm{eV}$ [23].

Fourier transformed infrared spectroscopy (FTIR) spectra were obtained using a Nicolet 8700 FTIR spectrometer coupled to a germanium crystal operated at $45^{\circ}$ using OMNIC 6.2 software (Thermo Electron Corp., Hampton, $\mathrm{NH}$ ). Two replicates of each membrane sample were measured, and five readings were taken from different points. Each spectrum represents an average of 16 scans collected in the range 600 to $4000 \mathrm{~cm}^{-1}$ at a resolution of $1 \mathrm{~cm}^{-1}$ [22].

\subsection{Short-term bacterial adhesion}

For the bacterial adhesion tests, a non-pathogenic strain of E. coli was used [25,26]. The bacterial strains were tagged with a plasmid coding for green fluorescent protein to allow live cell detection with fluorescent microscopy. The E. coli cells were incubated and harvested during the mid-exponential growth phase in Trypton (TT) media at $37^{\circ} \mathrm{C}$. E. coli $\mathrm{K} 12$ wild-type strain $\mathrm{MG} 1655$ was grown overnight in nutrient broth at $37^{\circ} \mathrm{C}$. The bacterial solution was transferred to narrow test tubes. Membrane coupons, with dimensions of approximately $1 \mathrm{~cm}^{2}$, were cut from the flat sheets and placed in $10 \mathrm{~mL}$ cell suspension. The tubes were then placed in an incubator at a temperature of $37^{\circ} \mathrm{C}$ for $4 \mathrm{~h}$. The individual tubes were gently shaken hourly to ensure complete exposure of the membrane surface to the bacterial suspension. The membrane coupons were then rinsed gently for a few seconds with a bacteria-free broth media to remove weakly bound cells. After the exposure to bacteria, the specimens were dried either in vacuum for a couple of hours or with dry nitrogen for a few minutes. Membrane coupons were then inspected under a fluorescent microscope, and six images were taken across the membrane surface.

\subsection{Long-term biofouling experiments}

For the long-term biofouling experiments, the membrane fouling simulator (MFS) with external dimensions of $0.07 \mathrm{~m} \times 0.20 \mathrm{~m} \times 0.04 \mathrm{~m}$ was used [27]. The MFS has shown to be a suitable tool for prediction and characterization of membrane fouling [28-30]. Membrane sheets were cut from an unused commercial RO membrane, TFC-HR, manufactured by Koch Membrane Systems (USA). For all studies a $34 \mathrm{mil}(864 \mu \mathrm{m})$ thick feed spacer was used, resulting in a flow channel porosity of $\approx 0.85$. Membrane and feed spacer coupons were placed in the MFS resulting in the same spatial dimensions as in spiral wound membrane systems. Both MFSs were operated parallel, and the development of the fouling was monitored by measuring the pressure drop over the MFSs in time. At the end of the study, the MFSs were opened, and the sheets of spacer and membrane were analysed for fouling amount and presence of coating.

The MFSs were fed with tap water, and the flow rate was set to $16 \mathrm{~L} \cdot \mathrm{h}^{-1}$ equal to a linear flow velocity of $0.16 \mathrm{~m} \cdot \mathrm{s}^{-1}$, representative for practice [31]. The flow rate was automatically kept constant for sensitive and accurate pressure drop measurements $[32,33]$. To enhance biofilm growth a solution of sodium acetate, sodium nitrate, and sodium dihydrogen orthophosphate in a mass ratio C:N:P of 100:20:10, respectively, was employed increasing the $\mathrm{C}$ concentration in the MFS feed water with $400 \mu \mathrm{g} \cdot \mathrm{L}^{-1}$. The typical C:N:P ratio in biomass is $\approx 100: 20: 4$.3. An excess of phosphorous was dosed to ensure that phosphate limitation did not restrict biofilm formation in the MFSs [34].

\subsubsection{Evaluation of the biomass concentration}

Adenosine triphosphate (ATP) was selected as parameter to quantify biomass accumulation. The selection of the biomass parameter ATP was based on earlier studies $[35,36]$. ATP measurements were performed using an ATP analyser (Advanced Luminometer, Celsis, Belgium).

\subsubsection{Visual inspection}

Confocal Laser Scanning Microscopy (CLSM), (LSM710 upright confocal microscope, Zeiss, Germany) was used to identify and characterize biofouling on the membrane surface after the experiments. The samples were stained with the following dyes based on methods described in the literature $[37,38]$. For total bacterial cells 4',6-Diamidino-2-Phenylindole (DAPI) dye (excitation wavelength of $358 \mathrm{~nm}$; emission wavelength of $461 \mathrm{~nm}$ ) was used. Fluorescein Isothiocyanate (FITC) (excitation wavelength of 480 $\mathrm{nm}$; emission wavelength of $520 \mathrm{~nm}$ ) was applied to stain the amine-reactive compound-like proteins and amino sugars, and Calcofluor White (excitation wavelength of $355 \mathrm{~nm}$; emission wavelength of $433 \mathrm{~nm}$ ) to stain $\beta$-D-glucopyranose polysaccharides. After each of these three staining stages, the sample was washed twice with phosphate-buffered saline (PBS) with $\mathrm{pH}$ of seven to remove excess stain, and a wipe was used to remove excess dye. At the end of the eight days experimental run the monitors were opened and $0.5 \times 0.5 \mathrm{~cm}^{2}$ samples were cut off from the membrane at three different locations (MFS: inlet, middle, and outlet) for CLSM analysis. Each membrane sample was analysed at four locations, resulting in a total of 12 images for each monitor. The images were taken with $1 \mu \mathrm{m}$ steps over the height, resulting in an average of 120 images per sample (indicating that the biofilm thickness was about $120 \mu \mathrm{m}$ ).

The fouling on the membrane surface was analysed by Scanning Electron Microscopy (SEM-EDX, Magellan, FEI). The samples were freeze dried for environmental SEM.

\subsubsection{Biofilm composition: bacterial cells, polysaccharides and proteins}

CLSM images were further analysed using ISA3D software [39] to quantify the differences in biofilms com- 
position. The biovolume of the total bacterial cells, polysaccharides and proteins were evaluated.

\section{Results}

In this study, the impact of membrane coating by amphiphilic copolymers on biofilm formation for biofouling control in reverse osmosis systems was investigated, applying short and long-term biofouling studies with coated and uncoated membrane sheets and feed spacers. The presence of the coating on the membrane was evaluated before and after the biofouling studies. The impact of the applied coating on water permeation was shown by Matin et al. [18] and was not the objective of this study.

\subsection{Membrane characterization}

Zeta potential measurements confirmed the presence of the coating on the membrane surface prior to the biofouling studies. In the range of $\mathrm{pH} 5$ to 10 the coated membrane showed a less negative surface charge compared to the uncoated membrane (Fig. 1a). X-ray photoelectron microscopy established the presence of fluorine functional groups on the coated membrane surface, caused by the presence of the perfluorodecyl acrylate (Fig. 1b).

Membrane surface roughness was evaluated by AFM in tapping mode in air. The coated membrane had a lower surface roughness $\left(R_{\mathrm{ms}}=488 \mathrm{~nm}, R_{a}=435 \mathrm{~nm}\right)$ than the uncoated membrane $\left(R_{\mathrm{ms}}=261 \mathrm{~nm}, R_{a}^{a}=213 \mathrm{~nm}\right)$. Where $R_{\mathrm{ms}}$ is the root mean square height and $R_{a}^{a}$ is the arithmetic mean height. The lower surface roughness of the coated membrane can be explained by the presence of polymer coating, filling the "valleys" of the membrane, reducing the overall membrane surface roughness (Fig. 2) [40].

All measurements confirmed the presence of the coating on the coated membrane sheets. The coated membrane had a less negative surface charge and a lower surface rough-
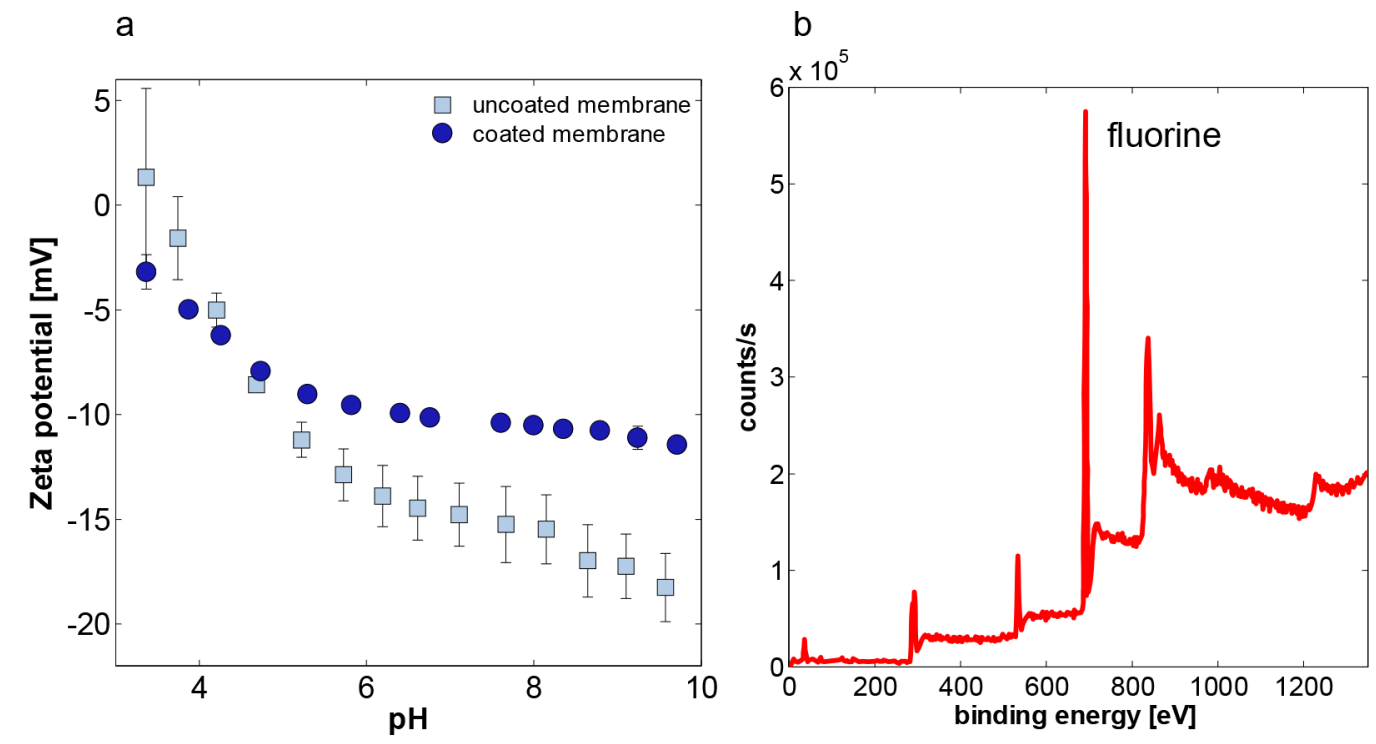

Fig. 1. Zeta potential (a) as a function of the $\mathrm{pH}$ for the uncoated and coated membranes and X-ray photoelectron spectroscopy (XPS) (b) for the coated clean, unused membrane. The XPS peak at $700[\mathrm{eV}]$ binding energy corresponds to the fluorine functional group present in the coating.
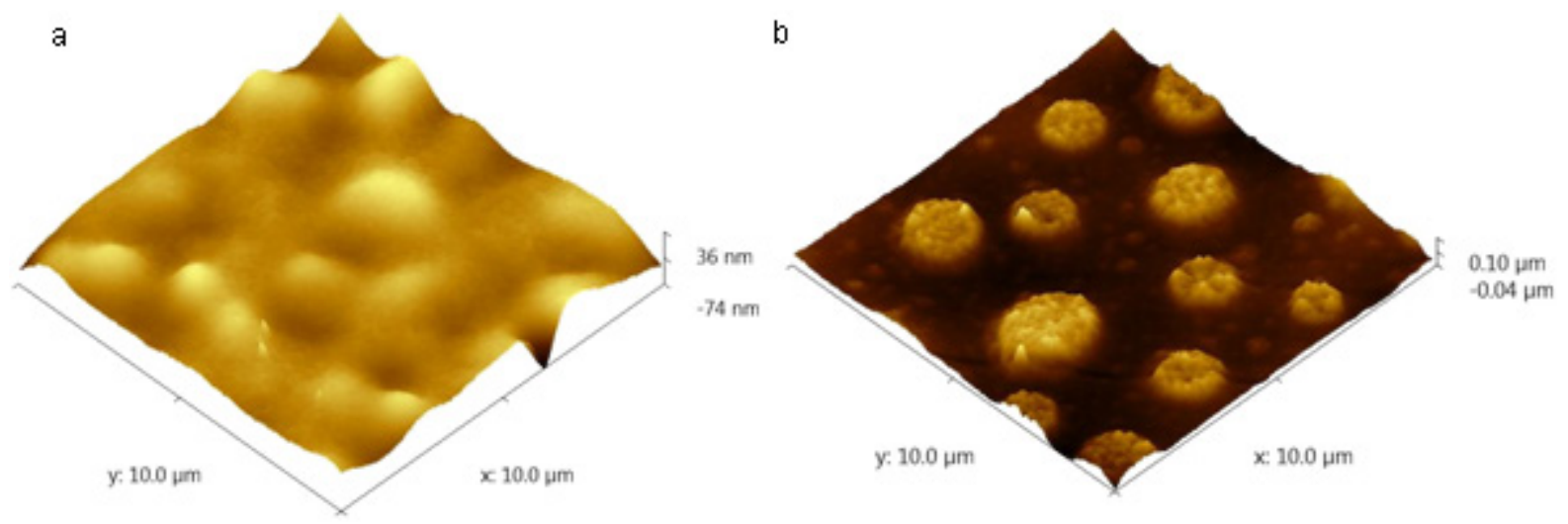

Fig. 2. Surface roughness of the (a) un-coated and (b) coated membranes measured by atomic force microscopy (AFM). A lower surface roughness was observed for the coated membrane. 
ness compared to the uncoated commercially available reverse osmosis membrane. Fluorine was detected on the coated membrane surface.

\subsection{Short-term bacterial adhesion tests}

The antifouling properties of the coated membrane were evaluated by short-term static bacterial adhesion experiments. The high fluorescence intensity on the surface of the uncoated membrane corresponds to an abundance of attached bacterial cells (Fig. 3a). The same trend was shown by bacterial cell counts (Fig. 3b). The results showed that compared to the uncoated membrane, the bacterial cell adhesion for the coated membrane was reduced by $70-90 \%$.

All measurements showed that the presence of the coating strongly reduced the attachment of the bacterial cells.

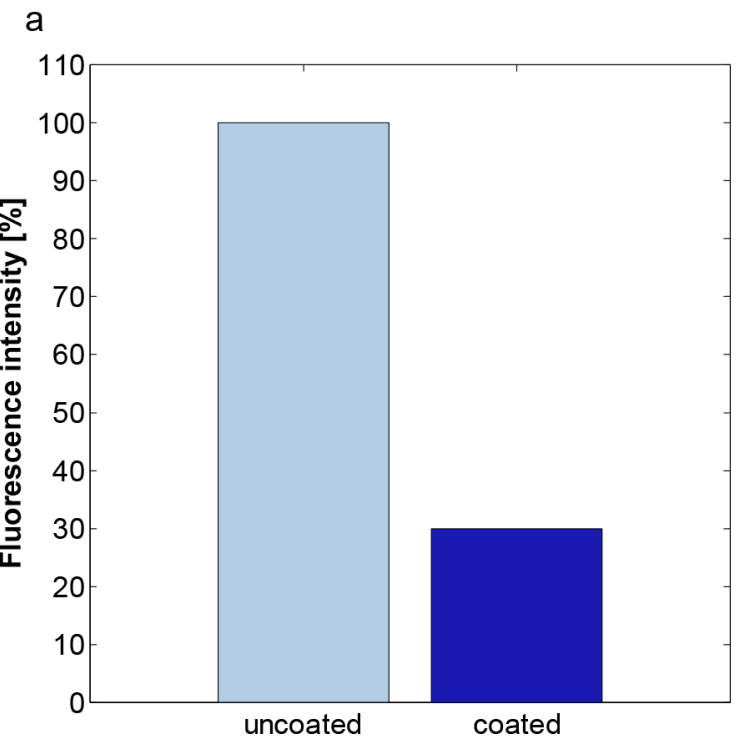

\subsection{Long-term biofouling studies}

Long-term biofouling studies were performed to evaluate the impact of a membrane coating on biofouling development. MFS units were run in parallel at similar operational conditions. To enhance the biofilm development, water supplemented with biodegradable nutrients was dosed to the MFS unit with uncoated and coated materials. As control, MFS units were operated without nutrient dosage containing coated and uncoated membrane and feed spacer sheets.

\subsubsection{Pressure drop development and biomass accumulation}

During the experimental period, feed channel pressure drop was monitored as an indicator of biofilm development.

The control monitors without nutrient dosage showed no pressure drop increase during the eight day study and

b

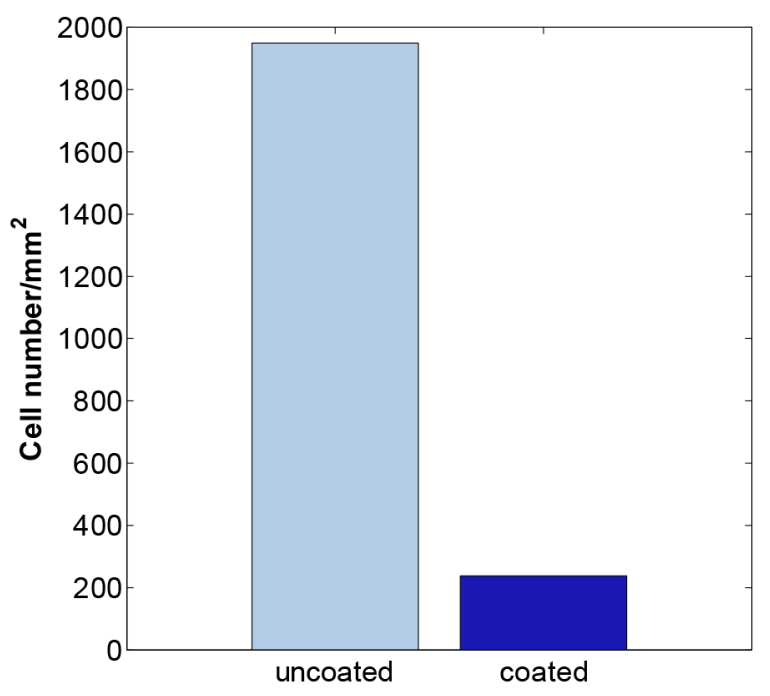

Fig. 3. Normalized fluorescence intensity (a) and attached bacterial cell number (b) for the uncoated and coated membranes after $4 \mathrm{~h}$ contact with a suspension of $E$. coli cells $(\mathrm{OD} 600=0.8)$.
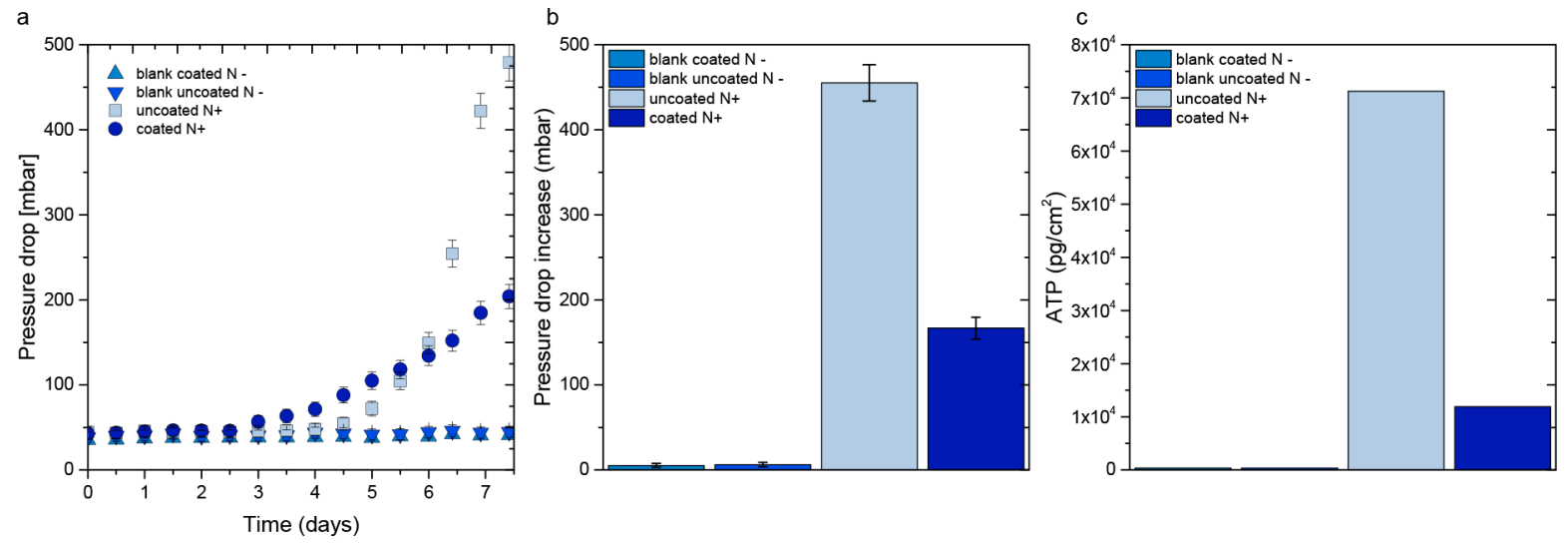

Fig. 4. Feed channel pressure drop (a) in time and (b) pressure drop increase due to biomass accumulation, and (c) amount of accumulated biomass at the end of the experimental period. The monitors containing the uncoated and coated membrane were fed with water containing biodegradable nutrient $\left(\mathrm{N}^{+}\right)$while the blanks had no nutrient dosage $\left(\mathrm{N}^{-}\right)$. Error bars indicate variation of the replica experiments. 
no significant accumulation of biomass for the coated and uncoated membrane and feed spacer (Fig. 4).

For the monitors with nutrient dosage the feed channel pressure drop strongly increased after the third day of the study, indicating biofilm development. After day 6 of the experimental period a stronger pressure drop increase was observed for the uncoated membrane (Fig. 4a).The coated membrane and feed spacer showed a lower pressure drop increase (Fig. 4b) and lower biomass accumulation (Fig. 4c) at the end of the 8 day monitor study compared to the monitor study operated with the uncoated membrane. So membrane coating caused a decrease in both pressure drop increase and biomass accumulation.

\subsubsection{Biomass characterization}

Results from SEM imaging of the biofilm after the experimental period are shown in Fig. 5. For the control membranes (uncoated and coated) without nutrient dosage no biofilm was observed on the membrane surfaces (Fig. 5a).

With nutrient dosage, the presence of biofilm on the membrane surface was confirmed on both the uncoated (Fig. 5b) and coated membranes (Fig. 5c). Less bacterial cells and more EPS were visible on the SEM images for the biofilm formed on the coated membrane surface (Fig. 5c) compared to the biofilm formed on the uncoated membrane (Fig. 5b). Colours (bacterial cells - green, EPS - blue) were applied in the SEM images to emphasize the presence of bacterial cells and EPS.

The data from Confocal Laser Scanning Microscopy (CLSM) images were averaged for each set of samples. CLSM images obtained for the fouled membrane surfaces confirmed that the biofilm formed on the coated membrane contained more EPS (polysaccharides and proteins) and less bacterial cells than the biofilm formed on the uncoated membrane (Fig. 6). CLSM images indicated that the biofilm on the coated membrane was $\approx 50 \%$ thinner than the biofilm formed on the uncoated membrane.

Further analyses of the CLSM images with ISA3D software were carried out to assess the biovolume of the bacterial cells, polysaccharides and proteins [39]. These calculations confirmed once again the presence of less bacterial cells but more EPS material for the coated membrane, compared to the uncoated membrane. Moreover, composition of the EPS significantly differed between the coated and uncoated membrane surface: more proteins and less polysaccharides were found on the coated membrane surface (Fig. 7).

Significant differences were found in the biofilms formed on the coated and uncoated membranes in terms of thickness and composition. On the uncoated membrane more bacterial cells and polysaccharides were observed, while on the coated membrane proteins strongly dominated.

\subsection{Stability of the applied coating}

To determine the stability of the coating on the membrane, a comparison was made between (i) the coated unused membrane (clean), (ii) the coated membrane after 8 days crossflow operation with biofilm development in the MFS (biofouled), (iii) and the fouled membrane after cleaning by sonification.

A unique characteristic for the coating, fluorine was found on the virgin, biofouled and cleaned membrane (FTIR: Fig. 8a,b fluorine peaks at $1240 \mathrm{~cm}^{-1}$ and $1205 \mathrm{~cm}^{-1}$ ) and on the biofouled membrane (XPS: Fig. 9b), indicating the coating was still completely present on the coated membrane after crossflow operation causing biofilm development and after subsequent harsh sonifier cleaning.

The biofouled coated membrane after removal of the biofilm by sonification had a lower zeta potential profile compared to the clean (unused) coated membrane (Fig. 9a). The lower surface charge of the fouled membrane may be explained by the incomplete removal of the biofouling layer by sonification.

The amphiphilic copolymer coating was well attached to the membrane and was not removed during cross-flow biofouling experiments and subsequent sonifier cleaning (as determined by two independent analytical methods) after the MFS studies.
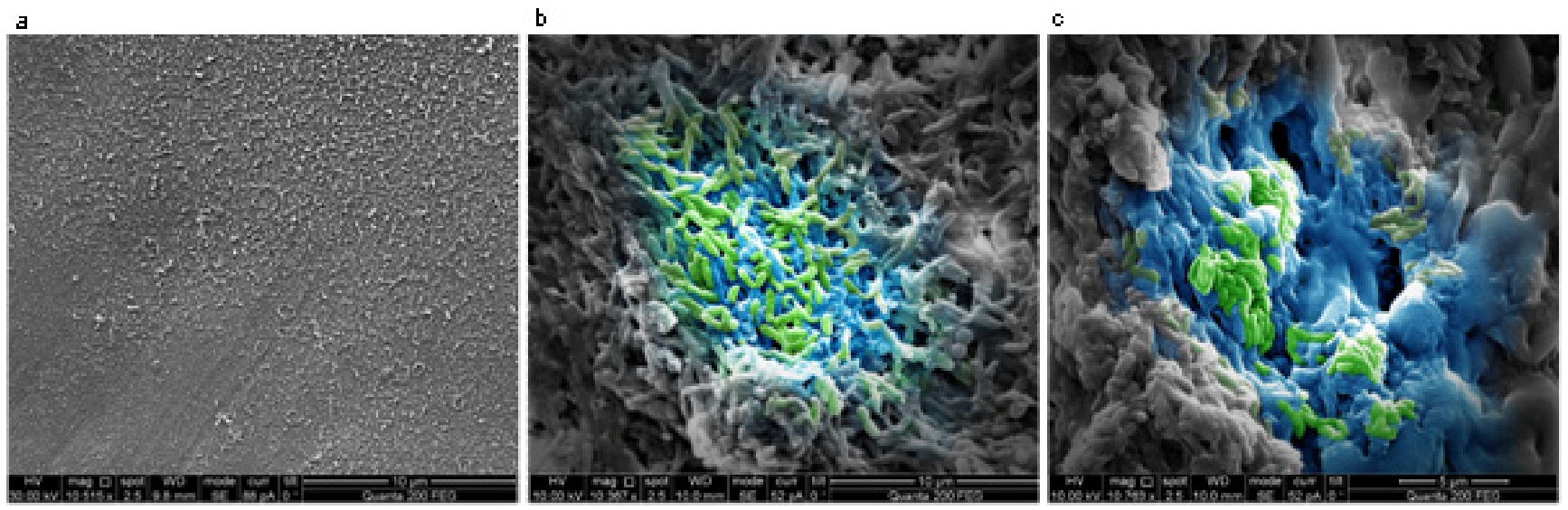

Fig. 5. Scanning electron microscopy (SEM) images of the (a) blank, (b) uncoated and (c) coated membrane at the end of the $8 \mathrm{~d}$ monitor experiment. No biofilm was observed on the blank membrane (no nutrient dosage). Bacterial cells (green) and extracellular polymeric substances (EPS, blue) were detected for the biofilm formed on the uncoated and coated membrane with nutrient dosage. The colors were applied to emphasize the bacterial cells and EPS. 


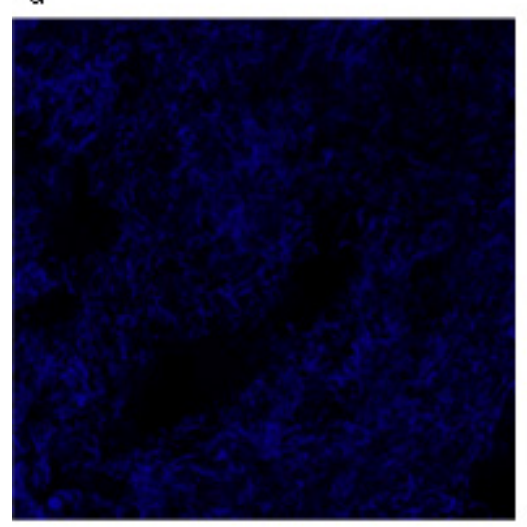

b

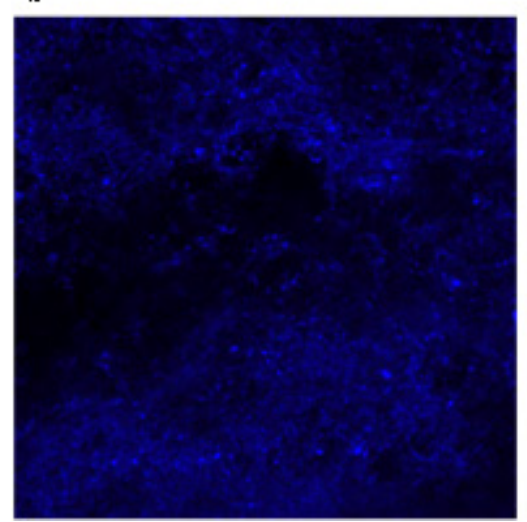

$\mathrm{c}$

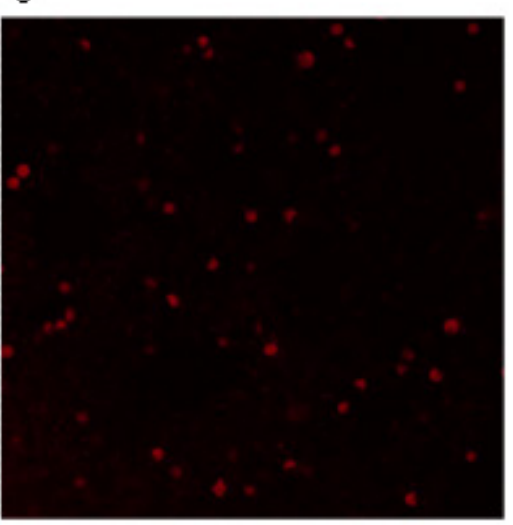

d

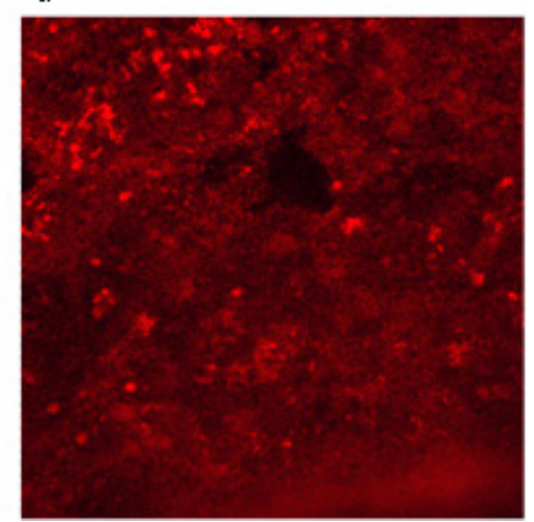

e

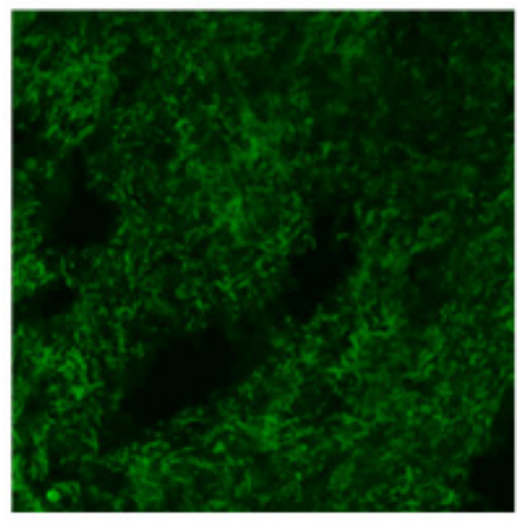

$f$

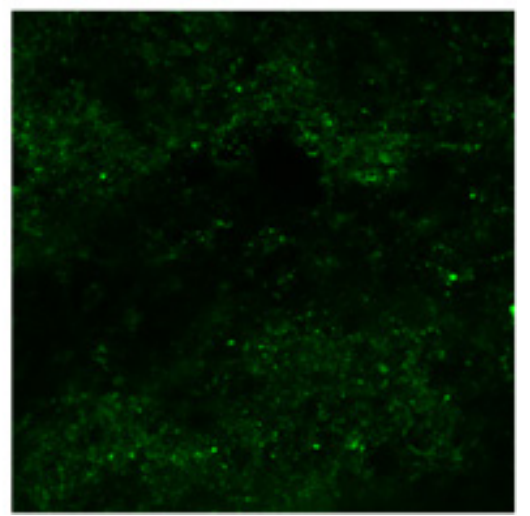

Fig. 6. Confocal laser scanning microscopy (CLSM) images of biofilms formed on the uncoated (top row) and coated (bottom row) membrane. The images show $(a, b)$ the polysaccharides in blue color, $(c, d)$ the proteins with red in the biofilm matrix and $(e, f)$ shows the bacterial cells in green color. The images were taken after $8 \mathrm{~d}$ of monitor operation.

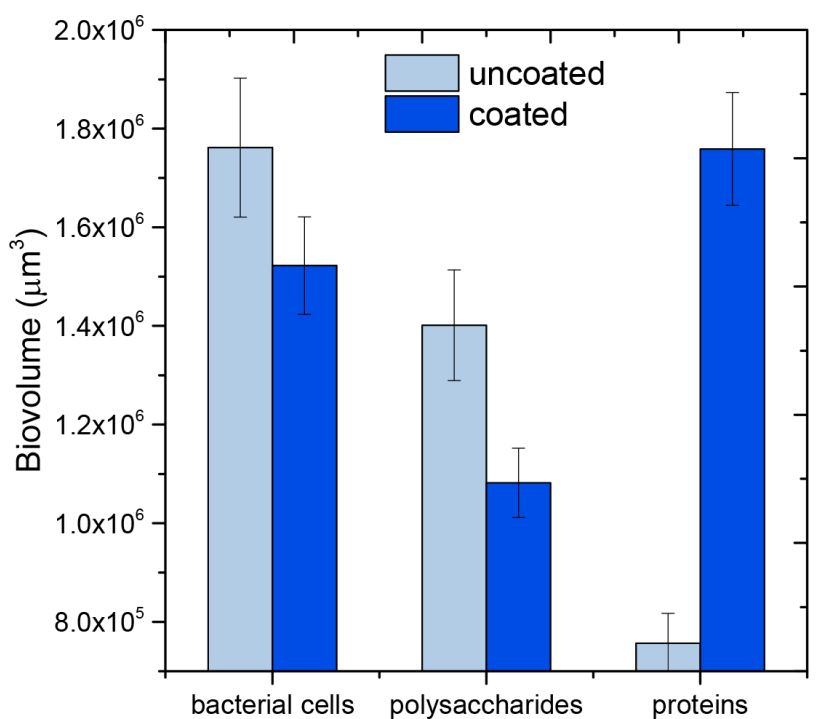

Fig. 7. Biovolume quantification based on the CLSM images. The biofilm formed on the uncoated membrane contained more bacterial cells and less EPS than the biofilm formed on the coated membrane. Significant differences were observed in the EPS composition of the biofilms formed on the coated and uncoated membrane. On the uncoated membrane the polysaccharide content was highest, while on the coated membrane proteins strongly dominated.

\section{Discussion}

The objectives of this study were to evaluate (i) the impact of an amphiphilic membrane coating on biofouling control, and (ii) the stability of the membrane coating. In the MFS studies the coated membrane and feed spacer showed a lower pressure drop increase and less biomass accumulation compared to the MFS operated with the uncoated membrane (Fig. 3). The developed biofilms were different in composition: the biofilm formed on the coated membrane contained less polysaccharides and bacterial cells but more proteins (Figs. 5-7). The results showed that the coating was strongly attached to the membrane surface and was still completely present after 8 days biofouling experiment (Figs. 8 and 9). The outcome of this study shows that biofouling can be restricted, although not avoided by the tested amphiphilic membrane coating.

\subsection{Impact of the coating on membrane properties}

Membrane coatings are applied to eliminate or reduce membrane fouling by changing surface properties [7]. In general, the presence of a coating increases the membrane thickness and resistance leading to a clean water flux reduction $[7,41]$. Earlier studies showed that the applied amphiphilic coating has a limited impact only on the permeate flux [18]. 
a

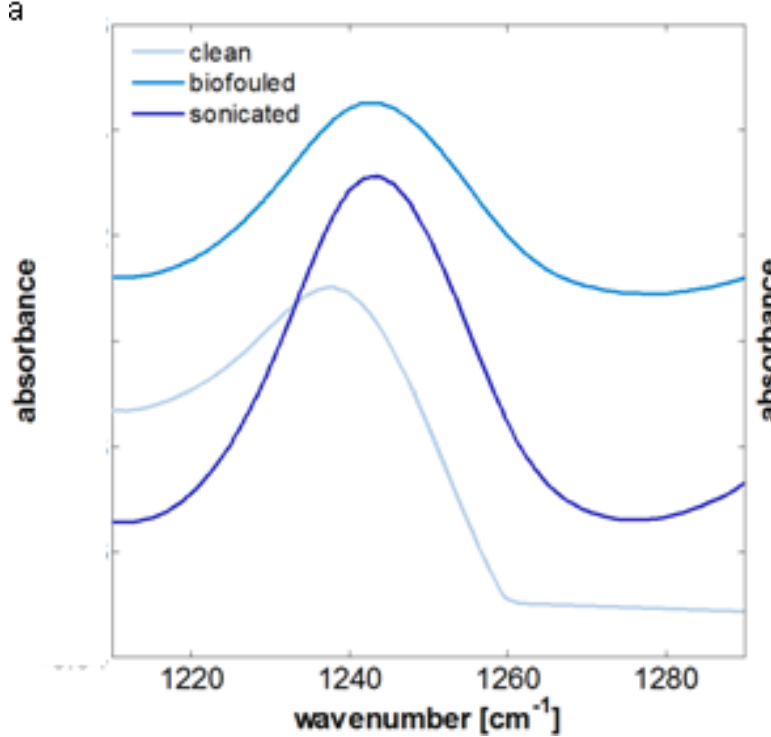

b

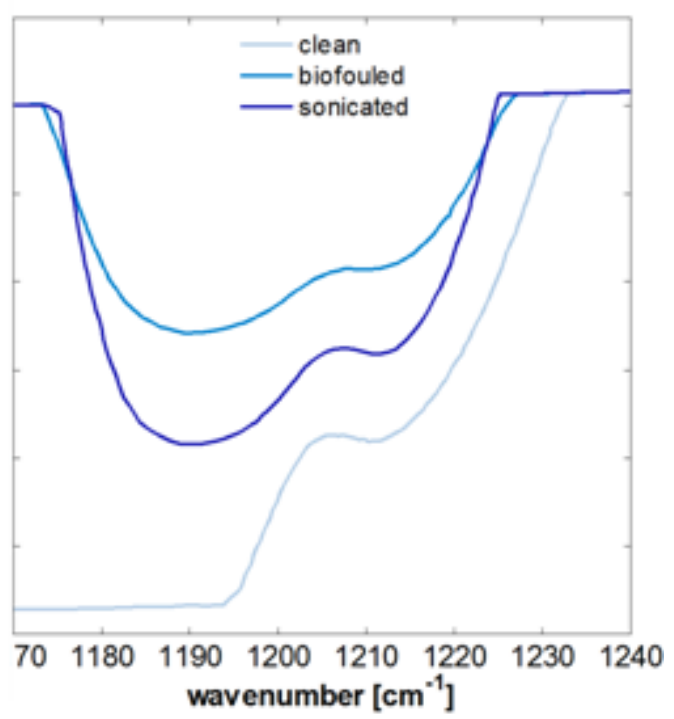

Fig. 8. Fourier transformed infrared spectroscopy (FTIR) spectra of coated membrane before the study (coated), at the study end (biofouled) and at the end of the study after removing the biofouling layer (cleaned). Fluorine peaks (a) at $1240 \mathrm{~cm}^{-1}$ and (b) at 1205 $\mathrm{cm}^{-1}$ were found on all three samples of the coated membranes.

a

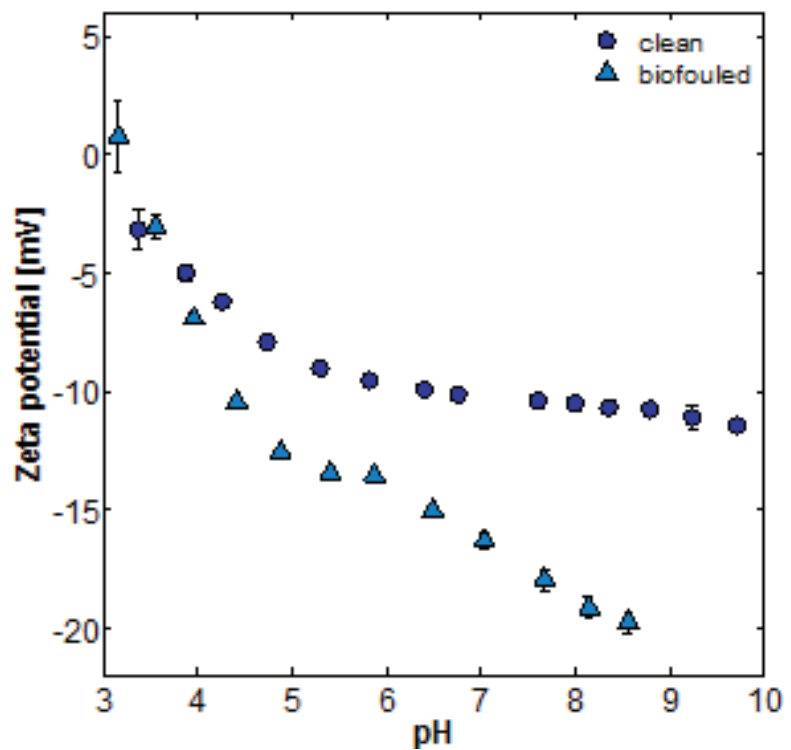

b

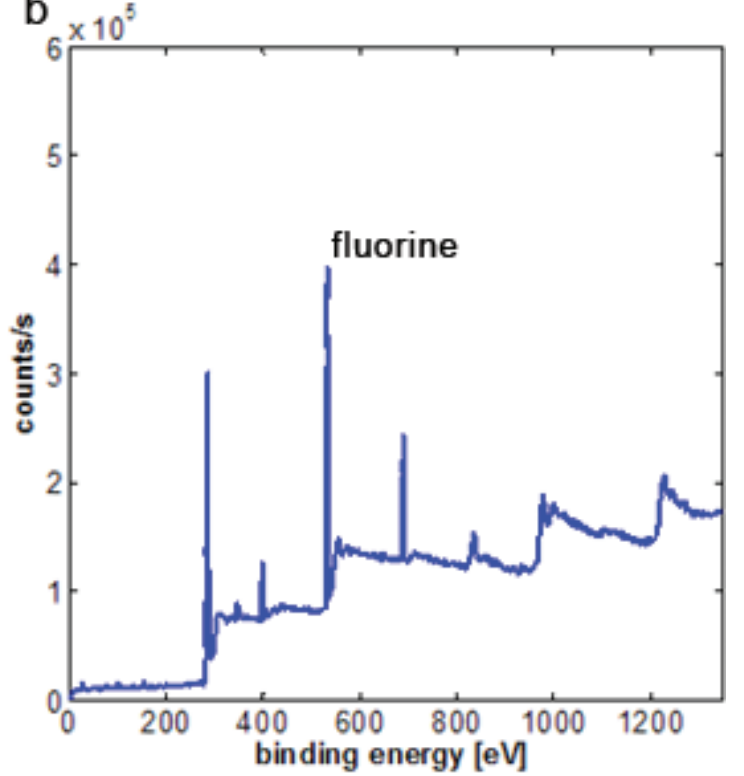

Fig. 9. Zeta potential (a) as a function of the $\mathrm{pH}$ for the coated membranes before and after the biofouling experiment and XPS (b) for the coated membrane after the biofouling experiment. The XPS peak at $700[\mathrm{eV}]$ binding energy corresponds to the fluorine functional group present in the coating on the membrane.

\subsection{Need for long-term biofouling studies}

In many investigations, short-term (2-6 h) static protein or bacterial cell adhesion tests were performed [11,42-44]. In some other cases short-term (2-24 h) cross-flow or dead end filtration tests were used to evaluate the impact of the coating on biofilm accumulation [9,16,45-47].

Short-term studies provide insight into initial protein or bacterial cell attachment to the membrane surface, but do not predict biofilm development or fouling behaviour
$[16,24,44]$. Therefore, long-term MFS studies are required. Miller et al., [44] showed that long-term biofouling studies were representative for practice, while short-term protein and bacterial adhesion tests were not, in agreement with the findings of this study. To evaluate the anti-fouling potential of a modified membrane and/or feed spacer long-term biofilm studies has to be carried out, under representative conditions for practice $[6,27,41,44]$. In this study eight day runs were performed to evaluate the impact of an amphiphilic coating on biofilm development. 
In practice biofilm development usually is a slow process. Therefore it is proposed to do longer-term studies under well controlled conditions.

\subsection{Impact of the coating on the biofouling rate}

The microorganisms in biofilms live in a self-produced matrix of hydrated extracellular polymeric substances (EPS) [48]. EPS consists mainly of polysaccharides and proteins, providing the mechanical stability of biofilms, and mediate their adhesion to surfaces [48]. Bacterial cell-membrane surface interaction is important in the early stage of biofilm development [49,50]. Surface properties such as roughness, charge and free energy impact bacterial cell attachment [9,51]. Extracellular proteins play an important role in bacterial attachment, with a strong polysaccharide production in mature biofilms $[50,52]$. Under stress, bacterial cells in biofilms produce more proteins than polysaccharides [48,53]. Zhang et al. [54] reported that long-term nanosilver exposure did not change the membrane fouling rate although the EPS concentration increased significantly, indicating that membrane modification affects EPS production.

Membrane surface modification by the amphiphilic coating resulted in a lower surface charge (Fig. 1) with a smoother surface (Fig. 2) causing slower biofilm development (Figs. 3, 4). The difference in pressure drop increase (caused by biofilm development) between the coated and uncoated membrane becomes significant after six days. Less and slower biofilm development on the coated membrane may be explained by less bacterial cell attachment, more cell detachment or both. In other words, less cells accumulated on the coated membrane but more EPS especially proteins were produced by the biofilm, which is in agreement with literature $[9,48,50-54]$.

\subsection{Coating stability}

Few studies on the application of coated membranes to control fouling reported on the coating stability $[6,55,56]$. Brzozowska et al. [55] observed a weak attachment of polymer brushes to the membrane surface. The coating layer was easily removed by lateral forces [55]. Experiments with silver nanoparticle coated feed spacers showed silver leaching during a flow cell fouling study [57]. Similar results were found with silver coated membranes (unpublished data). On the contrary, Louis et al. [41] reported the presence of a polyether-polyamide block copolymer coating on the membrane surface at the end of a 106 days fouling experiment.

The success of the application of a coating to control fouling is determined by the presence of the coating at the end of the study. Application of a coating for fouling control is only feasible when the coating is still present after long periods.

The long-term presence of a coating is hardly reported. Two recently published papers reported the presence of the coating after fouling studies $[55,56]$. Out of the 30 most cited papers on membrane coating for biofouling control using the Scopus database on 2 November 2015, only one paper reported after a long-term fouling study the presence of coating on the membrane [41]. Long-term lab scale studies are a first step to show the feasibility of membrane coating.
In practice, reverse osmosis membrane modules are used for much longer periods than the long-term lab scale studies. Therefore, coating stability may become critical when chemical cleaning is applied to prevent or control fouling. The impact of membrane coating should be evaluated not only in terms of biofouling, but also (i) how the formed biofilm composition and morphology are affected [58], (ii) on membrane cleanability $[59,60]$ and (iii) on coating stability.

It is recommended to report results of studies with coatings that were not effective to prevent, reduce or delay fouling development in membrane systems. When results of studies with coatings that do not effect fouling development are not published, other research groups may do similar studies.

\subsection{Future studies}

Membrane coating influences the biofilm composition and morphology. The same amount of biomass differing in composition and/or morphology may have a different impact on membrane performance. Although biofilm formation is not prevented by the coating, it can significantly impact (delay) the performance decline. Biofouling studies with coated and uncoated membranes should include determination of the biofilm composition, density and morphology under practice conditions involving the development of permeate flux, salt rejection and feed channel pressure drop in time.

Membrane coating can affect the membrane cleanability. A change in biofilm composition can result in a loosely attached biofilm that can be removed by e.g. hydraulic cleaning. Moreover, changes in biofilm composition can enhance diffusion of chemicals into the biofilm during chemical cleanings. Therefore, studies addressing advanced cleaning strategies of membrane systems should be considered to determine the impact of coated membranes on cleaning effectiveness. The assessment of the stability of a membrane coating after fouling and cleaning experiments should be included in the studies.

\section{Conclusions}

Studies were done with an amphiphilic coated and uncoated reverse osmosis membrane involving (i) long-term biofouling studies using membrane fouling simulators and (ii) assessment of the coating presence and physical characteristics before and after biofouling studies including cleaning by sonification. The coated and uncoated membranes were compared based on pressure drop development, accumulated biomass amount and characterization of the biofilm composition (bacterial cells, polysaccharides, proteins).

Based on the results, it can be concluded that:

- amphiphilic copolymer coating

1. delayed the pressure drop increase (a factor 3 lower than the uncoated membrane),

2. delayed biofilm formation (a factor 6 lower active biomass amount than the uncoated membrane),

3. did restrict, but not prevent biofilm formation,

4. influenced the biofilm composition (23\% lower polysaccharide and $132 \%$ higher protein content than the uncoated membrane), 
5. was present on the membrane and spacer before and after the biofouling study, and after sonification treatment, indicating the coating was strongly attached to the membrane and spacer until the end of the biofouling study.

- 8 day biofouling studies were found to be good predictors of biofouling while short-term surface adhesion tests were not.

\section{Acknowledgments}

The research reported in this publication was supported by funding from King Abdullah University of Science and Technology (KAUST) and Evides Industriewater. The authors are grateful to the Center for Clean Water and Clean Energy at King Fahd University of Petroleum \& Minerals (KFUPM) and Massachusetts Institute of Technology (MIT) for funding the research via project no. R5-CW-08. Al-Saeed (KFUPM) is appreciated for XPS analyses of membrane samples.

\section{References}

[1] H.-C. Flemming, Reverse osmosis membrane biofouling, Exp. Therm. Fluid Sci., 14 (1997) 382-391.

[2] J.S. Vrouwenvelder, S.A. Manolarakis, J.P. van der Hoek, J.A.M van Paassen, W.G.J. van der Meer, J.M.C. van Agtmaal, H.D.M. Prummel, J.C. Kruithof, M.C.M. van Loosdrecht, Quantitative biofouling diagnosis in full scale nanofiltration and reverse osmosis installations, Water Res., 42 (2008) 4856-4868.

[3] M.C.M. van Loosdrecht, L. Bereschenko, A. Radu, J.C. Kruithof, C. Picioreanu, M.L. Johns, J.S. Vrouwenvelder, New approaches to characterizing and understanding biofouling of spiral wound membrane systems., Water Sci. Technol., 66 (2012) 88-94.

[4] A. Matin, Z. Khan, S.M.J. Zaidi, M.C. Boyce, Biofouling in reverse osmosis membranes for seawater desalination: Phenomena and prevention, Desalination, 281 (2011) 1-16.

[5] M.A. Shannon, P.W. Bohn, M. Elimelech, J.G. Georgiadis, B.J. Mariñas, A.M. Mayes, Science and technology for water purification in the coming decades., Nature, 452 (2008) 301310.

[6] J.S. Louie, I. Pinnau, I. Ciobanu, K.P. Ishida, A. Ng, M. Reinhard, Effects of polyether-polyamide block copolymer coating on performance and fouling of reverse osmosis membranes, J. Membr. Sci., 280 (2006) 762-770.

[7] G. Kang, Y. Cao, Development of antifouling reverse osmosis membranes for water treatment: A review., Water Res., 46 (2012) $584-600$

[8] I.C. Kim, K.H. Lee, Dyeing process wastewater treatment using fouling resistant nanofiltration and reverse osmosis membranes, Desalination, 192 (2006) 246-251.

[9] A.C. Sagle, E.M.V. Wagner, H. Ju, B.D. McCloskey, B.D. Freeman, M.M. Sharma, PEG-coated reverse osmosis membranes: Desalination properties and fouling resistance, J. Membr. Sci., 340 (2009) 92-108.

[10] Y.-H. Zhao, B.-K. Zhu, L. Kong, Y.-Y. Xu, Improving hydrophilicity and protein resistance of poly(vinylidene fluoride) membranes by blending with amphiphilic hyperbranched-star polymer, Langmuir, 23 (2007) 5779-5786

[11] Z. Yi, L.-P. Zhu, Y.-Y. Xu, Y.-F. Zhao, X.-T. Ma, B.-K. Zhu, Polysulfone-based amphiphilic polymer for hydrophilicity and fouling-resistant modification of polyethersulfone membranes, J. Membr. Sci., 365 (2010) 25-33.

[12] C.Y. Tang, Y.-N. Kwon, J.O. Leckie, Effect of membrane chemistry and coating layer on physiochemical properties of thin film composite polyamide RO and NF membranes, Desalination, 242 (2009) 168-182.
[13] P.A. Araújo, D.J. Miller, P.B. Correia, M.C.M. van Loosdrecht, J.C. Kruithof, B.D. Freeman, D.R. Paul, J.S. Vrouwenvelder, Impact of feed spacer and membrane modification by hydrophilic, bactericidal and biocidal coating on biofouling control, Desalination, 295 (2012) 1-10.

[14] A. Matin, H.Z. Shafi, Z. Khan, M. Khaled, R. Yang, K. Gleason, F. Rehman, Surface modification of seawater desalination reverse osmosis membranes: Characterization studies and performance evaluation, Desalination, 343 (2014) 128-139.

[15] A. Venault, Y.H. Liu, J.R. Wu, H.S. Yang, Y. Chang, J.Y. Lai, P. Aimar, Low-biofouling membranes prepared by liquidinduced phase separation of the PVDF/polystyrene-b-poly (ethylene glycol) methacrylate blend, J. Membr. Sci., 450 (2014) 340-350.

[16] A. Asatekin, E.A. Olivetti, A.M. Mayes, Fouling resistant, high flux nanofiltration membranes from polyacrylonitrile-graftpoly(ethylene oxide), J. Membr. Sci., 332 (2009) 6-12.

[17] S.H. Baxamusa, K.K. Gleason, Journal of membrane, Adv. Funct. Mater., 19 (2009) 3489-3496.

[18] A. Matin, G. Ozaydin-Ince, Z. Khan, S.M.J. Zaidi, K. Gleason, D. Eggenspiler, Random copolymer films as potential antifouling coatings for reverse osmosis membranes, Desal. Water Treat., 34 (2011) 100-105.

[19] Sz.S. Bucs, R.V. Linares, M.C.M. van Loosdrecht, J.C. Kruithof, J.S. Vrouwenvelder, Impact of organic nutrient load on biomass accumulation, feed channel pressure drop increase and permeate flux decline in membrane systems, Water Res., 67 (2014) 227-242.

[20] J.S. Vrouwenvelder, C. Hinrichs, W.G.J. Van der Meer, M.C.M. Van Loosdrecht, J.C. Kruithof, Pressure drop increase by biofilm accumulation in spiral wound RO and NF membrane systems: role of substrate concentration, flow velocity, substrate load and flow direction, Biofouling, 25 (2009) 543-555.

[21] J.S. Vrouwenvelder, D.A.A. Graf von der Schulenburg, J.C.C. Kruithof, M.L.L. Johns, M.C.M.C.M. van Loosdrecht, Biofouling of spiral-wound nanofiltration and reverse osmosis membranes: a feed spacer problem., Water Res. 43 (2009) 583-594.

[22] C.A. Amadei, R. Yang, M. Chiesa, K.K. Gleason, S. Santos, Revealing amphiphilic nanodomains of anti-biofouling polymer coatings, ACS Appl. Mater. Interfaces, 6 (2014) 4705-4712.

[23] R. Yang, E. Goktekin, M. Wang, K.K. Gleason, Molecular fouling resistance of zwitterionic and amphiphilic initiated chemically vapor-deposited (iCVD) thin films, J. Biomater. Sci. Polym. Ed., 25 (2014) 1687-1702.

[24] A. Matin, Z. Khan, K.K. Gleason, M. Khaled, S.M.J. Zaidi, A. Khalil, P. Moni, R. Yang, Surface-modified reverse osmosis membranes applying a copolymer film to reduce adhesion of bacteria as a strategy for biofouling control, Sep. Purif. Technol, 124 (2014) 117-123.

[25] X. Wei, Z. Wang, J. Chen, J. Wang, S. Wang, A novel method of surface modification on thin-film-composite reverse osmosis membrane by grafting hydantoin derivative, J. Membr. Sci., 346 (2010) 152-162.

[26] V. Kochkodan, S. Tsarenko, N. Potapchenko, V. Kosinova, V. Goncharuk, Adhesion of microorganisms to polymer membranes: a photobactericidal effect of surface treatment with $\mathrm{TiO}_{2}$, Desalination, 220 (2008) 380-385.

[27] J.S. Vrouwenvelder, J.A.M. van Paassen, L.P. Wessels, A.F. van Dam, S.M. Bakker, The membrane fouling simulator: a practical tool for fouling prediction and control, J. Membr. Sci., 281 (2006) 316-324.

[28] S. West, M. Wagner, C. Engelke, H. Horn, Optical coherence tomography for the in situ three-dimensional visualization and quantification of feed spacer channel fouling in reverse osmosis membrane modules, J. Membr. Sci., 498 (2015) 345-352.

[29] C. Dreszer, A.D. Wexler, S. Drusová, T. Overdijk, A. Zwijnenburg, H.-C. Flemming, J.C.C. Kruithof, J.S. Vrouwenvelder, In-situ biofilm characterization in membrane systems using optical coherence tomography: formation, structure, detachment and impact of flux change., Water Res., 67 (2014) 243-254.

[30] J.S. Vrouwenvelder, D.A.A.G. von der Schulenburg, J.C.C. Kruithof, M.L.L. Johns, M.C.M.C.M. van Loosdrecht, Biofouling of spiral-wound nanofiltration and reverse osmosis membranes: a feed spacer problem., Water Res., 43 (2009) 583-594. 
[31] C. Picioreanu, J.S. Vrouwenvelder, M.C.M. van Loosdrecht, Three-dimensional modeling of biofouling and fluid dynamics in feed spacer channels of membrane devices, J. Membr. Sci. 345 (2009) 340-354.

[32] S.S. Bucs, N. Farhat, A. Siddiqui, R.V. Linares, A. Radu, J.C. Kruithof, J.S. Vrouwenvelder, Development of a setup to enable stable and accurate flow conditions for membrane biofouling studies, Desal. Water Treat., 57(28) (2016) 12893-12901.

[33] J.S. Vrouwenvelder, J.A.M. van Paassen, J.C. Kruithof, M.C.M. van Loosdrecht, Sensitive pressure drop measurements of individual lead membrane elements for accurate early biofouling detection, J. Membr. Sci., 338 (2009) 92-99.

[34] J.S. Vrouwenvelder, F. Beyer, K. Dahmani, N. Hasan, G. Galjaard, J.C. Kruithof, M.C.M. Van Loosdrecht, Phosphate limitation to control biofouling., Water Res., 44 (2010) 3454-3466.

[35] J.S. Vrouwenvelder, J.A.M. van Paassen, J.M.C. van Agtmaal, M.C.M. van Loosdrecht, J.C. Kruithof, A critical flux to avoid biofouling of spiral wound nanofiltration and reverse osmosis membranes: Fact or fiction?, J. Membr. Sci., 326 (2009) 36-44

[36] S.S. Bucs, R.V. Linares, M.C.M. van Loosdrecht, J.C. Kruithof, J.S. Vrouwenvelder, Impact of organic nutrient load on biomass accumulation, feed channel pressure drop increase and permeate flux decline in membrane systems, Water Res., 67 (2014) 227-242

[37] M.-Y. Chen, D.-J. Lee, Z. Yang, X.F. Peng, J.Y. Lai, Fluorecen staining for study of extracellular polymeric substances in membrane biofouling layers, Environ. Sci. Technol., 40 (2006) 6642-6646.

[38] R.V. Linares, S.S. Bucs, Z. Li, M. AbuGhdeeb, G. Amy, J.S Vrouwenvelder, Impact of spacer thickness on biofouling in forward osmosis., Water Res. 57 (2014) 223-233.

[39] H. Beyenal, C. Donovan, Z. Lewandowski, G. Harkin, Threedimensional biofilm structure quantification., J. Microbiol. Methods, 59 (2004) 395-413.

[40] C.Y. Tang, Y.-N. Kwon, J.O. Leckie, Effect of membrane chemistry and coating layer on physiochemical properties of thin film composite polyamide RO and NF membranes, Desalination, 242 (2009) 149-167.

[41] J.S. Louie, I. Pinnau, M. Reinhard, Effects of surface coating process conditions on the water permeation and salt rejection properties of composite polyamide reverse osmosis membranes, J. Membr. Sci., 367 (2011) 249-255.

[42] A. Adout, S. Kang, A. Asatekin, A.M. Mayes, M. Elimelech, Ultrafiltration membranes incorporating amphiphilic comb copolymer additives prevent irreversible adhesion of bacteria., Environ. Sci. Technol., 44 (2010) 2406-2411.

[43] J.Y. Park, M.H. Acar, A. Akthakul, W. Kuhlman, A.M. Mayes, Polysulfone-graft-poly(ethylene glycol) graft copolymers for surface modification of polysulfone membranes., Biomaterials, 27 (2006) 856-865.

[44] D.J. Miller, P.A. Araújo, P.B. Correia, M.M. Ramsey, J.C. Kruithof, M.C.M. van Loosdrecht, B.D. Freeman, D.R. Paul, M. Whiteley, J.S. Vrouwenvelder, Short-term adhesion and longterm biofouling testing of polydopamine and poly(ethylene glycol) surface modifications of membranes and feed spacers for biofouling control., Water Res., 46 (2012) 3737-3753.

[45] S.S. Madaeni, N. Ghaemi, Characterization of self-cleaning RO membranes coated with $\mathrm{TiO}_{2}$ particles under UV irradiation, J. Membr. Sci., 303 (2007) 221-233.
[46] Y.F. Zhao, L.P. Zhu, Z. Yi, B.K. Zhu, Y.Y. Xu, Improving the hydrophilicity and fouling-resistance of polysulfone ultrafiltration membranes via surface zwitterionicalization mediated by polysulfone-based triblock copolymer additive, J. Membr. Sci., 440 (2013) 40-47.

[47] C. Wang, G.K. Such, A. Widjaya, H. Lomas, G. Stevens, F Caruso, S.E. Kentish, Click poly(ethylene glycol) multilayers on RO membranes: Fouling reduction and membrane characterization, J. Membr. Sci., 409-410 (2012) 9-15.

[48] H.-C. Flemming, J. Wingender, The biofilm matrix, Nat Rev Micro., 8 (2010) 623-633.

[49] R.J. Palmer, D.C. White, Developmental biology of biofilms: implications for treatment and control., Trends Microbiol., 5 (1997) 435-440.

[50] G. O'Toole, H.B. Kaplan, R. Kolter, Biofilm formation as microbial development., Annu. Rev. Microbiol., 54 (2000) 49-79.

[51] M. Quirynen, C.M. Bollen, The influence of surface roughness and surface-free energy on supra- and subgingival plaque formation in man. A review of the literature., J. Clin. Periodontol., 22 (1995) 1-14.

[52] G.M. Wolfaardt, J.R. Lawrence, R.D. Robarts, S.J. Caldwell, D.E Caldwell, Multicellular organization in a degradative biofilm community, Appl. Environ. Microbiol., 60 (1994) 434-446.

[53] P.S. Stewart, M.J. Franklin, Physiological heterogeneity in biofilms, Nat Rev Micro., 6 (2008) 199-210.

[54] C. Zhang, Z. Liang, Z. Hu, Bacterial response to a continuous long-term exposure of silver nanoparticles at sub-ppm silver concentrations in a membrane bioreactor activated sludge system, Water Res., 50 (2014) 350-358.

[55] A.M. Brzozowska, E. Spruijt, A. de Keizer, M.A. Cohen Stuart, W. Norde, On the stability of the polymer brushes formed by adsorption of ionomer complexes on hydrophilic and hydrophobic surfaces., J. Colloid Interface Sci., 353 (2011) 380-391.

[56] A. Ronen, S. Lerman, G.Z. Ramon, C.G. Dosoretz, Experimental characterization and numerical simulation of the anti-biofuling activity of nanosilver-modified feed spacers in membrane filtration, J. Membr. Sci., 475 (2015) 320-329.

[57] H.-L. Yang, J.C.-T. Lin, C. Huang, Application of nanosilver surface modification to RO membrane and spacer for mitigating biofouling in seawater desalination., Water Res., 43 (2009) 3777-3786

[58] J.S. Vrouwenvelder, J. Buiter, M. Riviere, W.G.J. van der Meer, M.C.M. van Loosdrecht, J.C. Kruithof, Impact of flow regime on pressure drop increase and biomass accumulation and morphology in membrane systems., Water Res., 44 (2010) 689702 .

[59] S.A. Creber, J.S. Vrouwenvelder, M.C.M. van Loosdrecht, M.L. Johns, Chemical cleaning of biofouling in reverse osmosis membranes evaluated using magnetic resonance imaging, J. Membr. Sci., 362 (2010) 202-210.

[60] E. Cornelissen, J.S. Vrouwenvelder, S. Heijman, X. Viallefont, D. Vanderkooij, L.P. Wessels, Periodic air/water cleaning for control of biofouling in spiral wound membrane elements, J. Membr. Sci., 287 (2007) 94-101. 